\title{
PENGARUH PERILAKU ORGANISASI TERHADAP PENINGKATAN PRODUKTIVITAS KERJA PEGAWAI DI DINAS PERPUSTAKAAN DAN KEARSIPAN KABUPATEN SIDENRENG RAPPANG
}

\author{
1)Sri Ramadani Nurul Fitri, ${ }^{2)}$ Saifullah \\ Fakultas IImu Sosial dan IImu Politik Universitas Muhammadiyah Sidenreng Rappang \\ sriramadaninf43162057@gmail.com \\ ifulsidrap06@gmail.com
}

\begin{abstract}
Abstrak
Tujuan penelitian ini yaitu untuk mengetahui pengaruh perilaku organisasi terhadap peningkatan produktivitas kerja pegawai di Dinas Perpustakaan dan Kearsipan Kabupaten Sidenreng Rappang. Populasi penelitian ini sebanyak 41 orang di Dinas Perpustakaan dan Kearsipan Kabupaten Sidenreng Rappang yang berusia 17 tahun ke atas. Sampel dalam penelitian ini yaitu 39 pegawai di Dinas Perpustakaan dan Kearsipan, berdasarkan teknik sampling jenuh dengan Tipe penelitian ini adalah deskriptif kuantitatif. Sumber data dalam penelitian ini yaitu data primer dan data skunder. Teknik pengumpulan data yang digunakan dalam penelitian ini adalah observasi, kuesioner, wawancara dan dokumentasi. Hasil dari pengaruh perilaku organisasi terhadapa peningkatan produktivitas kerja pegawai di Dinas Perpustakaan dan Kearsipan Kabupaten Sidenreng Rappang ternyata ternyata nilai $t$ hitung $\geq t$ tabel atau $4,493 \geq 2,026$, dan tingkat signifikan 0,000 . maka $\mathrm{HO}$ ditolak dan Ha diterima, artinya berpengaruh signifikan terhadap peningkatan produktivitas kerja $(\mathrm{Y})$ Besarnya pengaruh perilaku organisasi $(\mathrm{X})$ terhadap peningkatan produktivitas kerja $(Y)$ dapat dilihat dari koefisien determinasi $\left(r^{2}\right)$ yang digunakan untuk mengetahui besarnya pengaruh $(X)$ terhadap $(Y)$ dengan hasil yaitu $39,8 \%$. Sedangkan sisanya $100 \%-39,8 \%=60,2 \%$ (dipengaruhi oleh faktor lain) yang tidak termasuk dibahas dalam penelitian ini. Sehingga $39,8 \%$ masih tergolong rendahnya perilaku organisasi terhadap peningkatan produktivitas kerja pegawai di Dinas Perpustakaan dan Kearsipan Kabupaten Sidenteng Rappang.
\end{abstract}

Kata kunci: Pengaruh Perilaku Organisasi dan Produktivitas Kerja

\begin{abstract}
The purpose of this study was to determine the effect of organizational behavior on improving employee productivity at the Library and Archives Service of Sidenreng Rappang Regency. The population of this study were 41 people in the Office of Library and Archives of Sidenreng Rappang Regency aged 17 years and over. The sample in this study were 39 employees in the Department of Library and Archives, based on the sampling technique saturated with this type of research is descriptive quantitative. Sources of data in this study are primary data and secondary data. Data collection techniques used in this study were observation, questionnaires, interviews and documentation. The results of the influence of organizational behavior on the increase in work productivity of employees at the Office of Library and Archives of Sidenreng Rappang Regency, it turns out that the value of $t$ count $\geq t$ table or $4.493 \geq 2.026$, and a significant level of 0.000 . then $\mathrm{HO}$ is rejected and $\mathrm{Ha}$ is accepted, meaning that it has a significant effect on increasing work productivity (Y). Y) with a yield of 39.8\%. While the remaining $100 \%-39.8 \%=60.2 \%$ (influenced by other factors) which are not included in this study. So that $39.8 \%$ is still classified as low organizational behavior towards increasing the work productivity of employees at the Library and Archives Office of Sidenteng Rappang Regency.
\end{abstract}

Keywords: Effect of Organizational Behavior and Work Productivity 


\section{A. PENDAHULUAN}

Suatu Instansi dalam melaksanakan kegiatannya, akan berusaha mencapai tujuan yang telah ditetapkan sebelumnya. Satu hal yang penting yaitu bahwa keberhasilan berbagai aktivitas didalam instansi dalam mencapai tujuan bukan hanya tergantung pada keunggulan teknologi, dana operasi yang tersedia, sarana ataupun prasarana yang dimiliki, melainkan juga tergantung pada aspek sumber daya manusia. Faktor Sumber Daya Manusia ini merupakan elemen yang harus diperhatikan oleh Instansi, terutama bila mengingat bahwa era semakin canggih. hal ini memaksa setiap instansi harus dapat bekerja dengan lebih efisien, efektif dan produktif. Tingkat kompetinsi yang tinggi akan memacu untuk mempertahankan aspek sumber daya manusia.

Berdasarkan Undang - Undang Nomor 5 Tahun 2014 tentang Aparatur Sipil Negara harus menjadi pemeran utama dalam pemberian pelayanan kepada masyarakat secara prima, sehingga kesan buruk terhadap aparatur sipil Negara akan terkikis oleh kinerja, kompetensi, kualitas dan optimalisasi layanan yang diberikan. Tujuan organisasi Pemerintahan daerah adalah memberikan pelayanan kepada masyarakat, yang dalam hal ini birokrat lah unsur penyelenggara pemerintahan daerah tersebut. Produktivitas pada dasarnya mencakup sikap mental yang selalu mempunyai pandangan bahwa kehidupan hari kemarin harus lebih baik dari hari ini. Cara kerja hari ini harus lebih baik dari hari kemarin dan hasil kerja yang dicapai esok harus lebih baik dari yang diperoleh hari ini. (Payman J.Simanjuntak, 1987:34-35).

Penerapan PP nomor 45 tahun 2019 tentang meningkatkan produktivitas di Indonesia. Peningkatan produktivitas dalam manajemen yang efektif dapat dilakukan dengan cara mendukung pegawai agar memiliki kompetensi kerja yang tinggi, rendahnya kompetensi akan memunculkan ketidak mampuan dari pegawai dalam bekerja yang akan mempengaruhi produktivitas kerja mereka sehingga menghabat tujuan organisasi. Namun pada kenyataannya dalam proses berperilaku organisasi di Dinas Perpustakaan dan Kearsipan Kabupaten Sidenreng Rappang, masih ada saja pegawai yang melakukan tugas dan fungsinya sebagaimana mestinya sehingga mengakibatkan produktivitas kerja menurun. Pekerjaan yang pada hakikatnya telah mempunyai tugas dan fungsi pokok pada bidang masing-masing hanya dikerjakan oleh satu orang saja yang dianggap mampu untuk melakukan semua pekerjaan tersebut, meskipun bukan bidang yang ditanganinya.

Pengaruh Perilaku Organisasi sangat mempengaruhi produktivitas kerja karena setiap manusia pada hakikatnya mempunyai sejumlah kebutuhan menjadi tujuan dari kebutuhan. Prinsip yang umum berlaku bagi kebutuhan manusia adalah setelah kebutuhan itu terpuaskan atau terpenuhi.Salah satu indikator yang mempengaruhi dalam upaya meningkatkan produktivitas yang efektif dan efisien adalah perilaku organisasi. Produktivitas merupakan sikap mental yang mempunyai pandangan bahwa untuk kehidupan hari ini akan lebih baik dari hari kemarin dan hari esok adalah lebih baik dari hari ini. Produktivitas merupakan salah satu komponen yang harus dimiliki oleh suatu Instansi apabila ingin mencapai tujuan yang telah ditetapkan instansi.

Produktivitas adalah sikap mental yang selalu berusaha untuk melakukan perbaikan mutu kehidupan secara berkelanjutan melalui peningkatan efisiensi, efektivitas, dan kualitas. Pelayanan produktivitas segala bentuk yang dilaksanakan oleh pemerintah, Pemerintah Provinsi, Pemerintah Kabupaten/Kota, Badan Usaha Milik Negara/Dearah dalam rangka promosi, peningkatan, pengukuran, dan pemeliharaan tingkat produktivitas masyarakat, perusahaan dan instansi pemerintah. Peningkatan produktivitas diselenggarakan dengan prinsip relevan ,efektif,efisien, terukur, ramah lingkungan, dan berkelanjutan. Berdasarkan uraian di atas maka penelitian dapat merumuskan judul dalam penelitian ini yaitu Pengaruh Perilaku Organisasi terhadap Peningkatan Produktivitas Kerja Pegawai di Dinas Perpustakaan dan Kearsipan Kabupaten Sidenreng Rappang dengan tujuan untuk mengetahui pengaruh perilaku Organisasi di Dinas Perpustakaan dan Kearsipan Kabupaten Sidenreng Rappang, untuk mengetahui pengaruh Produktivitas Kerja di Dinas Perpustakaan dan Kearsipan Kabupaten Sidenreng Rappang, dan untuk mengetahui faktor-faktor yang mempengaruhi produktivitas kerja pegawai di Dinas 
Perpustakaan dan Kearsipan Kabupaten Sidenreng Rappang.

Perilaku Organisasi adalah suatu studi yang menyangkut aspek-aspek tingkah laku dalam suatu organisasi atau kelompok tertentu (Thoha, 2011. ). Perilaku organisasi (organizational behavior) adalah "bidang studi yang menyelidiki pengaruh yang dimiliki oleh individu, kelompok dan struktur terhadap perilaku dalam organisasi, yang bertujuan menerapkan ilmu pengetahuan guna meningkatkan keefektifan suatu organisasi (Robbins, 2011.)." Menurut Hanggreni, (2011:1) perilaku organisasi adalah sebuah bidang khusus yang memiliki pokok ilmu pengetahuan yang umum mencakup tiga faktor penentu perilaku dalam organisasi: individu, kelompok, dan struktur dan penerapannya untuk membuat organisasi bekerja lebih efektif. Menurut Perilaku Organisasi adalah bidang ilmu yang menyelidiki dampak dari pengaruh individu, kelompok dan struktur dalam orgaisas terhadap perilaku orang-orang yang terlibat didalamnya bertujuan untuk menyapulasikan pengetahuan tersebut dalam meningkatkan efektivitas organisasi (Robbins, 2011.).

Perilaku organisasi mengajarkan tiga factor penentu perilaku dalam organisasi meliputi : Individu, Kelompok dan Struktur Perilaku organisasi adalah suatu studi tentang perilaku manusia dalam pengaturan organisasi, hubungan antara individu dengan organisasi, dan organisasi itu sendiri. Perilaku (Behaviour) merupakan sebuah fungsi dari variable-variabel individual (Individual), variable-variabel keorganisasian (organizational) dan variable-variabel psikologikal (psychological)." (Winardi, 2014) menyatakan ada dua indikator perilaku organisasi yang terjadi dalam pelaksanaan struktural organisasi sebagai berikut :

1. Perilaku Individu dalam Organisasi. Sopiah (2008: 13) untuk dapat memahami perilaku individu dengan baik, terlebih dahulu kita harus memahami karakteristik yang melekat pada indvidu. Adapun karakteristik yang dimaksud adalah ciri-ciri biografis, kepribadian, persepsi dan sikap.

2. Perilaku Kelompok dalam Organisasi Kelompok merupakan bagian dari kehidupan manusia. Tiap hari manusia akan terlibat dalam aktivitas kelompok. Masing-masing dari kita telah menjadi dan masih menjadi anggota kelompok-
p-ISSN 2302-0970

e-ISSN 2723-0201

kelompok yang berbeda. Ada kelompok sekolah, kelompok kerja, kelompok keluarga, kelompok sosial, kelompok kegamaan, kelompok formal, dan kelompok informal (Ivancevichdkk,2006: 5).

Produktivitas adalah "suatu pendekatan yang interdisiplin untuk menentukan tujuan yang efektif, pembuatan tenatang aplikasi penggunaan cara yang produktif untuk menggunakan sumber-sumber secara efisien dan tetap menjaga kualitas yang tinggi yang mengikutsertakan sumber modal teknologi, manajemen, informasi, energy dan sumbersumber lain menuju kepada pengembangan dan peningkatan standar hidup untuk seluruh masyarakat (Sinungan, 2003). Produktivitas mengandung pengertian sikap mental yang selalu mempunyai pandangan mutu kehidupan hari ini harus lebih baik dari kemarin dan hari esok lebih baik dari hari . Produktivitas kerja adalah hasil kerja.,Hasil kerja merupakan hasil yang diperuntuk dari pekerjaan yang dilaksanakan untuk karyawan (Siagian, 2009).

Produktivitas kerja dapat dicapai dengan maksimal apabila mampu menciptakan efektivitas dan kreativitas (Umar, 2005 ). Indikator produktivitas kerja adalah sebagai berikut (Sutrisno, 2009):

1. Kemampuan. Mempunyai kemampuan untuk melaksanakan tugas. Kemampuankempuan seorang karyawan sangat bergantung pada keterampilan yang dimiliki serta 16 profesionalisme mereka dalam bekerja. Ini memberikan daya untuk menyelesaikan tugas-tugas yang diembannya kepada mereka.

2. Meningkatkan hasil yang dicapai. Berusaha untuk meningkatkan hasil yang akan dicapai. Hasil merupakan salah satu yang dapat dirasakan baik untuk yang mengerjakan maupun yang menikmati hasil pekerjaan tersebut. Jadi upaya untuk memanfaatkan produktivitas kerja bagi masing-masing yang terlibat dalam suatu pekerjaan.

3. Semangat kerja. merupakan usaha yang dialkukan agar lebih baik lagi dari hari kemarin. Indikator ini dapat dinilai dari etos kerja dan hasil yang dicapai dalam satu hari kemudian dibandingkan dengan hari sebelumnya.

4. Pengembangan diri. Senantiasa mengembangkan diri untuk meningkatkan kemampuan kerja. Pengembangan diri 
dapat dilakukan dengan melihat tantangan dan harapan dengan apa yang akan dihadapi. Karna semakin kuat tantanganny jadi,Pengembanga diri mutlak dilakukan. Begitu juga harapan untuk menjadi lebih baik akan sangat berdampak pada keinginanuntuk meningkatkan kemampuan.

5. Mutu. berusaha untuk meningkatkan mutu lebih baik dari yang telah lalu. Mutu merupakan hasil pekerjaan yang dapat menunjukkan kualitas kerja seorang pegawai. Jadi "menigkatkan mutu bertujuan untuk memberikan hasil yang terbaik yang pada gilirannya akan sangat berguna bagi perusahaan dan dirinya sendiri."

6. Efisiensi. Pebandingan antara hasil yang dicapai dengan keseluruhan sumber daya yang digunakan. Masukan dan keluaran merupakan aspek produktivitas yang memberikan pengaruh yang cukup signifikan bagi karyawanav.

\section{B. METODE PENELITIAN}

Penelitian ini penelitimenggunakan dua variabel yaitu variabel bebas Perilaku Organisasi (X) dan Variabel terikat Peningkatan Produktivitas Kerja (Y). Menurut (Sugiyono, 2010 : 117) "populasi adalah wilayah generalisasi yang terdiri atas obyek/subyek yang mempunyai kualitas karakteristik tertentu yang ditetapkan untuk penelitian untuk dipelajari kemudian ditarik kesimpulannya. Menurut (Sugiyono., 2013) teknik sampling adalah pengambilan sampel untuk menentukan sampel yang akan digunakan dalam penelitian, terdapat berbagai teknik sampling yang digunakan maka generalisasi kepada populasi yang diteliti. Penelitian ini, digunakan beberapa teknik pengumpulan data, yang meliputi: Observasi, Wawancara, Kuesioner(Angket), Dokumentasi dan StudiPustaka (Library Research). Teknik analisis data dilakukan analisis dengan bantuan tabel frekuensi dan SPSS 21.0. Data hasil penelitian dianalisis dengan alat statistik yang terdiri dari, analisis deskriptif, uji kualitas data, uji regresi linear sederhana.

\section{HASIL DAN PEMBAHASAN}

Hasil Penelitian rekapitulasi analisis desktiptif pada Tata cara / tingkah laku suatu kelompok sebanyak 50,77\%, Tingkah laku masing-masing pegawwai dalam
p-ISSN 2302-0970

e-ISSN 2723-0201

menjalankan tugas dan fungsi pokoknya sesuati standar SOP sebanyak 44,10\%, Tentang Sikap kekompakan yang diperlihatkan yang dilakukan dalam suatu devisi sebanyak 43,08\%

Hasil olahan data SPSS untuk menguji tingkat validitas data yakni di ketahui bahwa 3 item pertanyaan yang digunakan untuk mengukur variabel perilaku organisasi (X) dinyatakan valid dengan nilai corected itemtotal correlation lebih besar dari $>0.25,0.30$ (corected item-total correlation $>0.25,0.30$ ). Yaitu X1 : 0.226, X2 : 0.249, X3: 0.556. Berdaasarkan bahwa 11 item pertanyaan yang digunakan untuk mengukur variabel produktivitas kerja $(Y)$ dinyatakan valid dengan nilai corected item-total correlation lebih besar dari $>0.25,0.30$ (corected item-total correlation $>0.25,0.30$.

Berdasarkan output relibility ststistics kuesioner penelitian yang digunakan untuk mengukur variabel perilaku organisasi $(x)$ dapat diakatakan reliabel karena nilai Cronbach Alpha yang diperuntuk adalah sebesar 0.640 yang berarti lebih besar dari 0.60 (0.640> 0.60). Berdasarkan output relibility ststistics kuesioner penelitian yang digunakan untuk mengukur variabel produktivitas kerja (x) dapat dikatakan reliabel karena nilai Cronbach Alpha yang diperuntuk adalah sebesar 0.511 yang berarti lebih besar dari $0.60(0.511>0.60)$.

Output pada model summary menjelaskan nilai $R$ pada tabel di atas 0,631 , artinya kolerasi antara variabel perilaku organisasi terhadap produktivitas kerja sebesar 0,631, hal ini berarti adanya hubugan yang erat karena nilai mendekati 1 . Nilai $R^{2}$ sebesar $0,398 \times 100 \%=39,8 \%$ Sedangkan sisanya $100 \%-39,8 \%=60,2 \%$ dipengaruhi untuk variabel lain yang tidak termasuk dalam penelitian ini. Adjusted Rsquare adalah $\mathrm{R}$ square yang telah disesuaikan, nilai $R$ square sebesar 0,455 menunjukkan sumbangan pengaruh variabel independen terhadap variabel dependen Berdasarkan Coefficients, didapatkan nilai konstanta $(a)=22,073$ serta $t$ hitung $=4,943$ dan tingkat signifikan $=0,000$. jadi model regresi yang digunakan dalam penelitian ini untuk mengukur perilaku organisasi terhadap produktivitas kerja pegawai di Dinas Perpustakaan dan Kearsipan Kabupaten Sidenreng Rappang."
1. Ha:
Perilaku
berpengaruh/signifikan terhadap 
produktivitas kerja pegawai di Dinas Perpustakaan dan Kearsipan Kabupaten Sidenreng Rappang.

2. Ho:Perilaku organisasi tidak berpengaruh/signifikan terhadap produktivitas kerja pegawai di Dinas Perpustakaan dan Kearsipan Kabupaten Sidenreng Rappang.

Pengambilaan Keputusan :

1. Jika nilai $t$ hitung $\geq t$ tabel, jadi $\mathrm{HO}$ ditolak dan Ha diterima, artinya Signifikan

2. Jika nilai $t$ hitung $\leq \mathrm{t}$ tabel, jadi $\mathrm{HO}$ diterima dan $\mathrm{Ha}$ ditolak, artinya tidak Signifikan

Tabel Coefficients diperuntuk $\mathrm{t}$ hitung $=$ 4,493 prosedur mencari statistic tabel dengan kriteria

1. Tingkat signifikan $(a=0,05)$

2. $\mathrm{df}=$ Jumlah Responden -2 atau $39-2=37$

3. $\mathrm{t}$ tabel $=\mathrm{a} / 2 ; \mathrm{df}$

$=0,05 / 2 ; \mathrm{df}$

$=0,025 ; 37$ Maka $t$ tabel $=2,026$

Ternyata nilai $\mathrm{t}$ hitung $>\mathrm{t}$ tabel atau 4,493 > 2,026, jadi $\mathrm{HO}$ ditolak dan $\mathrm{Ha}$ diterima, artinya signifikan. Jadi, perilaku organisasi berpengaruh atau signifikan terhadap peningkatan produktivitas kerja pegawai di Dinas perpustakaan dan kearsipan Kabupaten Sidenreng Rappang.

\section{KESIMPULAN}

Berdasarkan hasil penelitian yang telah diuraikan pada bab sebelumnya jadi penulis dapat menarik kesimpulan: Hasil penelitian dan pembahasan, pengaruh perilaku organisasi (X) di Dinas Perpustakaan dan Kearsipan Kabupaten Sidenreng Rappang memiliki pengaruh yang signifikan dilihat dari tabel ANOVA, ternyata nilai $\mathrm{t}$ hitung $\geq \mathrm{t}$ tabel atau 4,493 $\geq 2,026$, dan tingkat signifikan 0,000 . jadi $\mathrm{HO}$ ditolak dan $\mathrm{Ha}$ diterima, artinya berpengaruh signifikan terhadap peningkatan produktivitas kerja $(Y)$. Besarnya pengaruh perilaku organisasi (X) terhadap peningkatan produktivitas kerja $(\mathrm{Y})$ dapat dilihat dari koefisien determinasi $\left(r^{2}\right)$ yang digunakan untuk mengetahui besarnya pengaruh $(\mathrm{X})$ terhadap $(\mathrm{Y})$ dengan hasil yaitu $39,8 \%$. Sedangkan sisanya $100 \%-39,8 \%=$ $60,2 \%$ (dipengaruhi untuk faktor lain) yang tidak termasuk dibahas dalam penelitian ini. Maka 39,8\% masih tergolong rendahnya perilaku organisasi terhadap peningkatan produktivitas kerja pegawai di Dinas
Perpustakaan dan Kearsipan Kabupaten Sidenteng Rappang.

\section{E. REFERENSI}

Muhammad Yusuf, S. (2020). Pengaruh Pengawasan Pimpinan terhadap Disiplin Kerja Pegawai Kantor Desa Carawali Kecamatan Watang Pulu Kabupaten Sidenreng Rappang. PRAJA, 155.

Robbins, S. d. (2011.). Perilaku Organisasi, Edisi Kedua belas. Jakarta: Penerbit Salemba Empat.

Siagian, S. P. (2009). Manajemen Sumber Daya Manusia, Edisi 1 Cetakan 17. Jakarta: Bumi Aksara.

Sinungan, M. (2003). Produktivitas. Jakarta: Bumi Aksara.

Sugiyono. (2013). Metode Penelitian Kuantitatif, Kualitatif dan R\&D. Bandung: Alfabeta.

Sutrisno, E. (2009). Manajemen Sumber Daya Manusia, Edisi Pertama. Jakarta: Kencana Prenada Media Grup.

Thoha, M. ( 2011. ). Perilaku Organisasi, Konsep Dasar dan Aplikasinya. Jakarta : Rajawali Pers.

Umar, S. A. (2005 ). Produktivitas Efektif. Bandung: Intermediai.

Winardi, J. (2014). Manajemen Perilaku Organisasi. Jakarta: Prenada Media Group. 